\title{
Model identification and parameter estimation for $\mathrm{LiFePO}_{4}$ batteries
}

\author{
CR Birkl*, DA Howey ${ }^{\dagger}$ \\ Energy and Power Group, Department of Engineering Science, University of Oxford, UK \\ *christoph.birkl@eng.ox.ac.uk \\ ${ }^{+}$david.howey@eng.ox.ac.uk
}

Keywords: Parameter estimation, current pulse, diffusion, lithium-ion battery

\begin{abstract}
We propose a method for dynamic model identification and parameter estimation of $\mathrm{LiFePO}_{4}$ cells based on current pulse measurements and electrochemical impedance spectroscopy (EIS). Modelling efforts were focused on diffusion as the predominant dynamic process relevant to battery management systems. An equivalent circuit model approach was adopted with parameters dependant on temperature and state of charge (SOC). The model was parameterised at $50{ }^{\circ} \mathrm{C}, 20{ }^{\circ} \mathrm{C}, 0{ }^{\circ} \mathrm{C}$ and $-30{ }^{\circ} \mathrm{C}$ and between $10 \%$ and $100 \%$ SOC. Initial parameter estimations for the model identification procedure were informed by EIS. The model was validated (at constant $\mathrm{SOC}$ ), for the entire temperature range and at C-rates between $\mathrm{C} / 2$ and $9 \mathrm{C}$, by voltage simulation based on a dynamic drive cycle profile. Maximal residuals did not exceed $68 \mathrm{mV}$ or $2 \%$ of the nominal cell voltage $\left(V_{\text {nom }}\right)$ and root-mean-square deviations remained within $28 \mathrm{mV}$ or $0.8 \%$ of $V_{\text {nom }}$ at all temperatures and C-rates.
\end{abstract}

\section{Introduction}

Equivalent circuit models (ECM) of battery dynamics are computationally more efficient than complex electrochemical battery models and therefore well suited to applications in battery management systems (BMS) for electric vehicles (EVs) or hybrid electric vehicles (HEVs) [1-3]. Model parameters are generally obtained either by means of electrochemical impedance spectroscopy (EIS) and fitting procedures in the frequency domain $[4,5]$, or by least-squares algorithms based on time domain data [2, 6]. The two methods are rarely unified for model development and parameterisation. As a result, ECM structures and elements based on EIS analyses can be misinterpreted when used in time-domain modelling. For instance, simple ECMs are often claimed to model charge transfer dynamics in the timedomain when, in fact, the time steps are too large to observe any dynamic charge transfer processes. Time constants of charge transfer dynamics in lithium ion (Li-ion) battery cells, at moderate operating temperatures $\left(>0{ }^{\circ} \mathrm{C}\right)$, are in the range of milliseconds [7,8], whereas BMS sampling rates are typically of the order of a few Hertz [9] maximum. The cell dynamics in this frequency range are dominated by diffusion mass transfer [8]. Figure 1 shows the relationship between time and frequency-domain data by means of a Nyquist plot in (a) and the voltage response to a current pulse in (b). Approximate frequency and time dependencies of the different processes occurring in a Li-ion battery are indicated in the plots. From this illustration it becomes clear that the predominant dynamic process at sampling frequencies below a few Hertz is diffusion.

In this work, we focus on modelling the cell dynamics at the frequencies governed by diffusion, with practical relevance for BMSs.
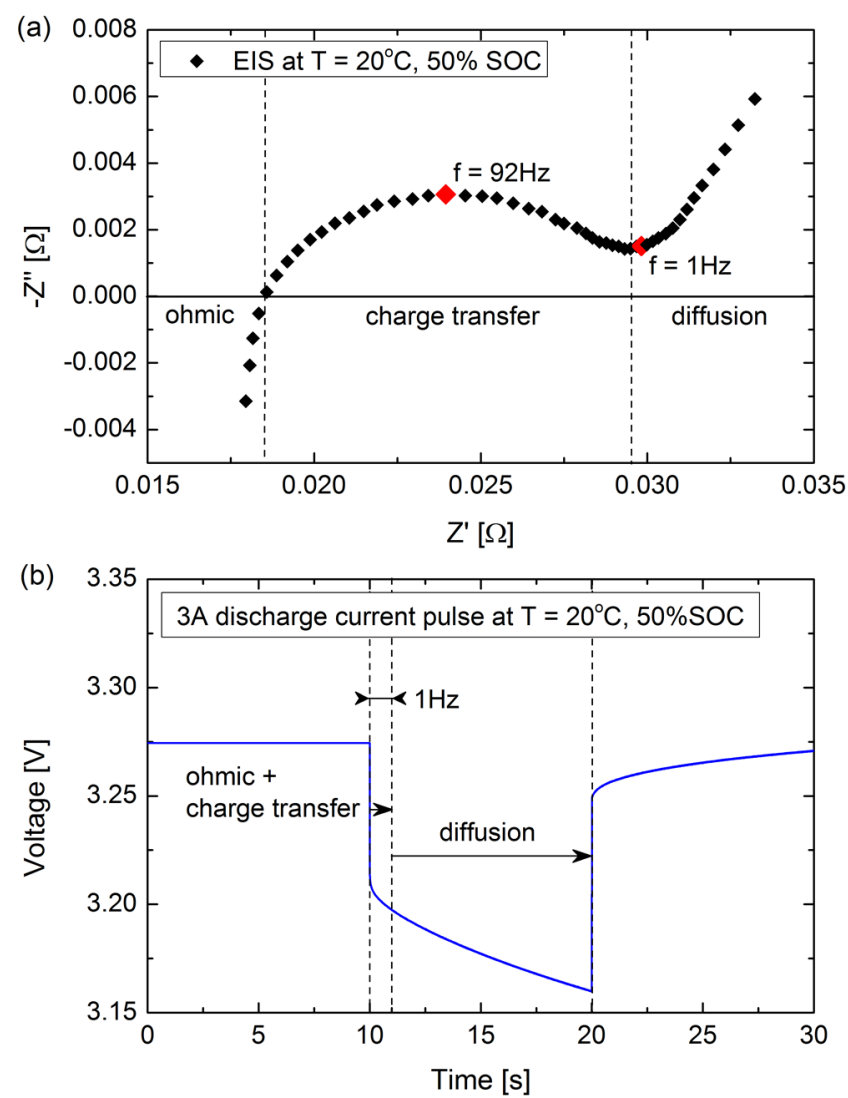

Figure 1: (a) Nyquist plot of impedance spectrum and (b) voltage response to a $3 \mathrm{~A}$ discharge current pulse recorded at $20{ }^{\circ} \mathrm{C}, 50 \%$ SOC.

We propose a simple and practical method for identification and parameterisation of a parameter-varying linear model, based on current pulse measurements. Model parameters vary with temperature and state of charge (SOC) and are estimated 
at $50{ }^{\circ} \mathrm{C}, 20{ }^{\circ} \mathrm{C}, 0{ }^{\circ} \mathrm{C}$ and $-30{ }^{\circ} \mathrm{C}$ and between $10 \%$ and $100 \%$ SOC. EIS serves for initial parameter guesses for the system identification algorithm. Ultimately, this modelling aproach will be integrated into a battery state observer to estimate SOC and state of health $(\mathrm{SOH})$ of $\mathrm{LiFePO}_{4}$ battery cells.

\section{Experimental}

The primary objective of the tests was to build up a data set which could be used to identify, parameterise and validate a parameter-varying linear model. Data was collected in both the frequency domain (EIS) and time domain (current pulse tests) in order to relate these to one another and demonstrate the possibility of using EIS data to obtain initial parameter guesses for model identification.

EIS and current pulse tests were carried out on a $1.1 \mathrm{Ah}$ $\mathrm{LiFePO}_{4}$ cell (APR18650 by A123Systems), at $50{ }^{\circ} \mathrm{C}, 20{ }^{\circ} \mathrm{C}$, $0{ }^{\circ} \mathrm{C}$ and $-30{ }^{\circ} \mathrm{C}$, using a BioLogic SP-150 potentiostat and thermal chamber. The cell's capacity was determined at each temperature, after a full discharge comprising a constant current (CC) discharge at $500 \mathrm{~mA}$ to a voltage of $2.0 \mathrm{~V}$ followed by constant voltage $(\mathrm{CV})$ discharge until the current dropped below $50 \mathrm{~mA}$. The capacity was determined by $\mathrm{CC}$ charging at $500 \mathrm{~mA}$ to a potential of $3.6 \mathrm{~V}$, followed by a CV charge until the current dropped below $50 \mathrm{~mA}$. The cell's capacity was measured to be $1.0 \mathrm{Ah}$ at ambient temperature upon initial testing. After the capacity test, EIS and current pulse tests were repeated between $100 \%$ and $10 \%$ SOC in steps of $10 \%$ SOC at every temperature. The sequence of test procedures is given as follows:

Steps 1) to 4) were conducted at $50{ }^{\circ} \mathrm{C}, 20{ }^{\circ} \mathrm{C}, 0{ }^{\circ} \mathrm{C}$ and $-30{ }^{\circ} \mathrm{C}$ :

1) Adjust temperature

2) Thermal equilibration for $90 \mathrm{~min}$

3) Capacity test by CCCV charge

4) Conduct steps a) to e) at $100 \%$ to $10 \%$ SOC in steps of $10 \%$ SOC:

a) Equilibration for $90 \mathrm{~min}$ after charge or after SOC adjustment

b) EIS measurement (see Section 2.1)

c) $10 \mathrm{~min}$ rest

d) Current pulse measurement (see Section 2.2)

e) Discharge at $500 \mathrm{~mA}$ to next scheduled SOC (based on cell's effective capacity).

\subsection{Electrochemical impedance spectroscopy (EIS)}

Impedance spectra were recorded in a frequency range between $5 \mathrm{kHz}$ and $50 \mathrm{mHz}$, with an ac current perturbation of $70 \mathrm{~mA}$, at a resolution of 10 points per decade and averaged over three measurements.

\subsection{Current pulse tests}

The current pulse pattern consisted of five subsequent discharge and charge current pulses. The current pulse magnitude was $2 \mathrm{~A}$ for tests at temperatures of $0{ }^{\circ} \mathrm{C}$ and above and $250 \mathrm{~mA}$ at $-30{ }^{\circ} \mathrm{C}$. Larger currents for the pulses ensure a good signal-to-noise ratio since the current pulse method does not employ averaging whereas EIS does. The maximum current is limited by the cell's power capability, which decreases significantly at low temperatures, therefore lower current pulses had to be used at $-30{ }^{\circ} \mathrm{C}$. A lower signal-to-noise ratio at this temperature is therefore expected and will affect the accuracy of parameters estimated. The cell's voltage response to the imposed current pulses was measured at a sampling rate of $1 \mathrm{~ms}$ and used for model identification and parameter estimation.

\subsection{Artemis drive cycle profiles}

For model validation based on a realistic dynamic cycle, a current profile was derived from the Artemis drive cycle [10] by differentiating the speed vector and scaling the profile to the desired maximum current. The profile features both negative (discharging) and positive (charging) currents, as well as rest periods, corresponding to EV or HEV operation including regenerative braking. The voltage response to Artemis profiles was recorded at a sampling rate of $1 \mathrm{~Hz}$.

\section{Dynamic model}

The dynamic model was designed to simulate the cell's terminal voltage response to any arbitrary current input over a wide range of temperatures, SOCs and C-rates. An accurate model of the cell's terminal voltage under a dynamic load will form the basis of a state observer, which will be implemented to estimate $\mathrm{SOC}$ and $\mathrm{SOH}$, in continuation of this work. The two principal model requirements were: (i) sufficient flexibility to allow for a large variability of parameters and (ii) a simple and practical method for parameter estimation. An equivalent circuit model approach was found to be well suited for this application. Cell processes with time constants lower than the typical sampling rate of a BMS (i.e. ohmic resistance and charge transfer) were modelled as ohmic resistors. The model dynamics simulate diffusion, which dominates the cell response at the sampling rates of interest. A computationally effective equivalent circuit representation of diffusion is the so called $Z_{\mathrm{ARC}}$ element [8]. It consists of a number of resistor, capacitor parallel branches $(R / / C)$ connected in series (see Figure 2).

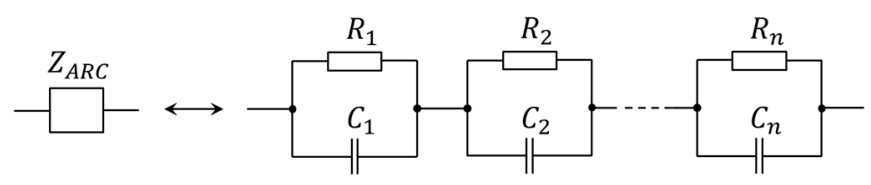

Figure 2: Equivalent circuit representation of $Z_{\mathrm{ARC}}$ element to model diffusion.

\subsection{Identification of the model structure}

Model identification and parameter estimation were carried out using MATLAB's ${ }^{\circledR}$ System Identification toolbox. A state space model of the form displayed in Equation (1), with identifiable parameters, was constructed. 


$$
\begin{aligned}
{\left[\begin{array}{c}
\dot{V}_{1} \\
\vdots \\
V_{n}
\end{array}\right] } & =\left[\begin{array}{ccc}
-\frac{1}{R_{1} C_{1}} & \cdots & 0 \\
\vdots & \ddots & \vdots \\
0 & \cdots & -\frac{1}{R_{n} C_{n}}
\end{array}\right]\left[\begin{array}{c}
V_{1} \\
\vdots \\
V_{n}
\end{array}\right]+\left[\begin{array}{c}
\frac{1}{C_{1}} \\
\vdots \\
\frac{1}{C_{n}}
\end{array}\right] I_{b a t} \\
V_{b a t} & =V_{1}+\ldots+V_{n}+R_{s} I_{b a t}
\end{aligned}
$$

The model states, $V_{l} \ldots V_{n}$, are the potential differences across elements $R_{l} / / C_{1} \ldots R_{n} / / C_{n}$, which consist of resistors $R_{1} \ldots R_{n}$ and capacitors $C_{1} \ldots C_{n} . I_{b a t}$ is the cell current and serves as the model input. The model output is the cell's terminal voltage, $V_{b a t}$, which is calculated as the sum of potential differences across all $R / / C$ elements and across the ohmic resistance $R_{s}$. Following common practice of model identification, equilibrium values of the voltage data were subtracted, hence the absence of a term for open circuit potential (OCP) in Equation (1). The model order (which corresponds to the number of $R / / C$ elements) was determined by minimising the loss function of the state space model when fitted to voltage measurements of the current pulse experiments. The minimisation was performed for a model order range from 1 to 5 and for data recorded between $0{ }^{\circ} \mathrm{C}$ and $50{ }^{\circ} \mathrm{C}$ at every SOC. For the majority of data sets (SOC between $10 \%$ and $90 \%$ ), the optimal model order was 2, which was thus selected for the ECM. The schematic of the identified ECM is depicted in Figure 3.

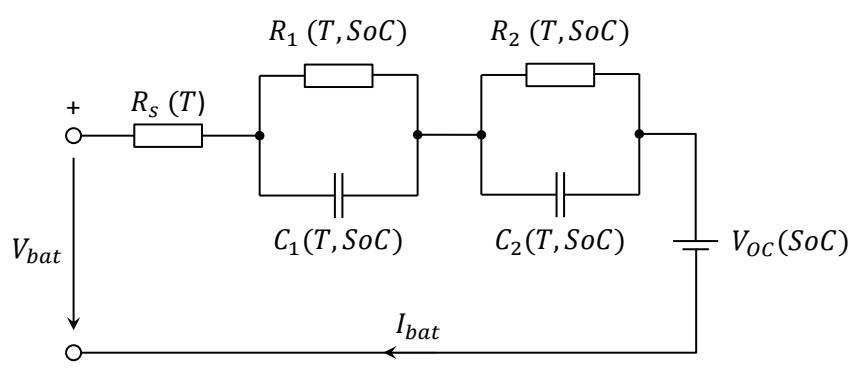

Figure 3: Identified equivalent circuit model

The resistor $R_{S}$ is comprised of ohmic and charge transfer resistance and $R_{1} / / C_{1}$ and $R_{2} / / C_{2}$ account for diffusion. Parameters were estimated at all temperatures and SOCs, as described in Section 3.2. Temperature and SOC dependencies are discussed in Section 4.1. The state space model representation is given in Equation (2).

$$
\begin{aligned}
{\left[\begin{array}{c}
\dot{V}_{1} \\
\dot{V}_{2}
\end{array}\right] } & =\left[\begin{array}{cc}
-\frac{1}{R_{1} C_{1}} & 0 \\
0 & -\frac{1}{R_{2} C_{2}}
\end{array}\right]\left[\begin{array}{c}
V_{1} \\
V_{2}
\end{array}\right]+\left[\begin{array}{c}
\frac{1}{C_{1}} \\
\frac{1}{C_{n}}
\end{array}\right] I_{b a t} \\
V_{b a t} & =V_{O C}+V_{1}+V_{2}+R_{s} I_{b a t}
\end{aligned}
$$

The terminology in Equation (2) is the same as that in Equation (1), with the addition of a term for OCP, $V_{O C}$.
Data recorded at $-30{ }^{\circ} \mathrm{C}$ were excluded from the identification procedure due to significant differences in cell dynamics. From Figure 4 it is clear that, at $-30{ }^{\circ} \mathrm{C}$, charge transfer dynamics are slowed down to an extent that the process becomes rate limiting for the entire recorded frequency range. Therefore, any dynamics modelled in the frequency range of interest (below $\sim 5 \mathrm{~Hz}$ ) represent charge transfer rather than diffusion and the physical interpretation of model parameters discussed above does not hold true for very low operating temperatures (e.g. $\left.-30^{\circ} \mathrm{C}\right)$.
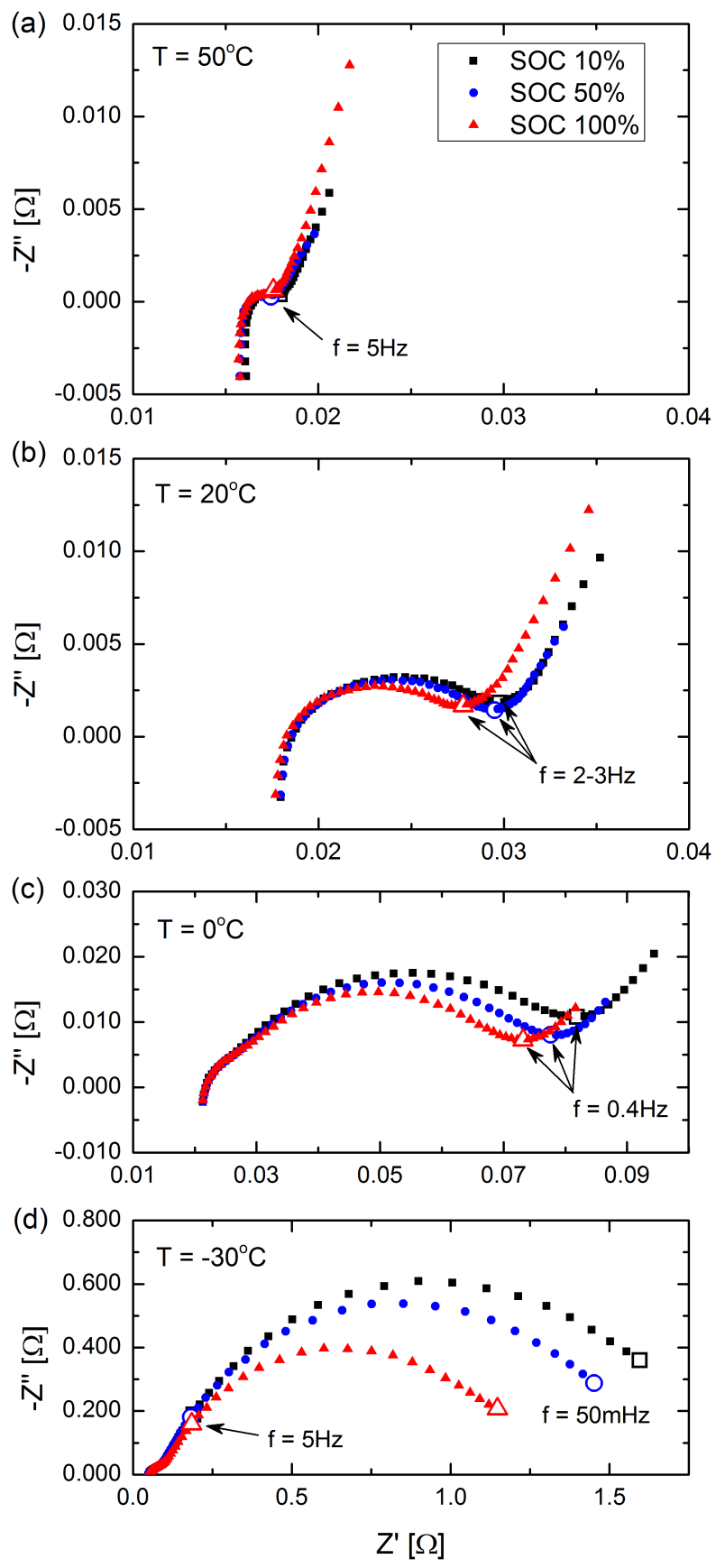

Figure 4: Nyquist plots of EIS at various temperatures and SOCs, as indicated in graphs. Note the different scales, which were necessary to maintain distinctive features of the individual impedance spectra. 


\subsection{Parameter estimation}

The model structure expressed in Equation (2) was used in a grey box model with identifiable parameters to estimate the model parameters at every temperature and SOC. Voltage measurements of the current pulse experiments were used for parameter estimation. Two options were investigated for the initiation of the model estimation algorithm: (i) all initial model parameters were set to zero and (ii) initial values for $R_{s}$ and the time constants $\tau_{1}$ and $\tau_{2}$ were approximated based on EIS data as follows: $R_{s}$ was estimated as the real part of the impedance at the frequency where the imaginary part reaches a minimum, in the range of $0 \mathrm{~Hz}$ to $5 \mathrm{~Hz}$ (these frequencies are indicated for all temperatures in Figure 4), and $\tau_{l}$ (where $\tau=R C$ ) as the time constant at that same frequency. $\tau_{2}$ was estimated as the time constant at the lowest sampling frequency, $50 \mathrm{mHz}$. These initial parameter estimations led to a significant improvement of the model fit to the current pulse data at low and high SOCs, as illustrated in Figure 5. The Root-mean-square deviation (RMSD) between experimental and simulated voltage differed between $4.8 \mathrm{mV}$ for initial model parameters set to zero and $1.6 \mathrm{mV}$ for initial parameters estimated from EIS data.
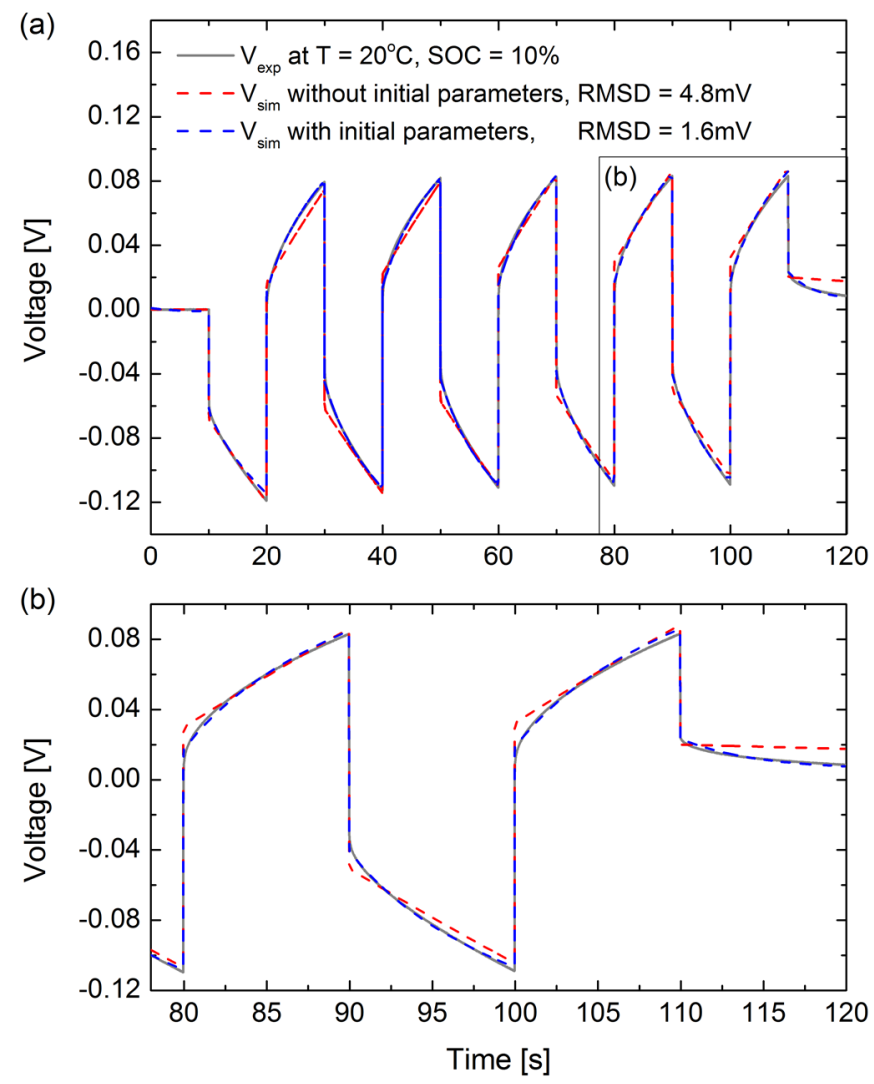

Figure 5: Voltage response to current pulse series recorded at $20^{\circ} \mathrm{C}, 10 \%$ SOC. The solid line depicts the measured, dashed lines the simulated voltages. (b) is the magnification of the indicated section in (a).

\section{Results}

\subsection{ECM parameters}

Model parameters were estimated at $50{ }^{\circ} \mathrm{C}, 20{ }^{\circ} \mathrm{C}, 0{ }^{\circ} \mathrm{C}$ and $-30{ }^{\circ} \mathrm{C}$ and at $100 \%$ to $10 \%$ SOC in steps of $10 \%$ SOC. Results for resistances and time constants are displayed in Figure 6. Parameters estimated at $-30{ }^{\circ} \mathrm{C}$ were excluded from this illustration and the following analysis, since neither their values (orders of magnitude larger than those of other temperatures) nor their physical interpretations are comparable.
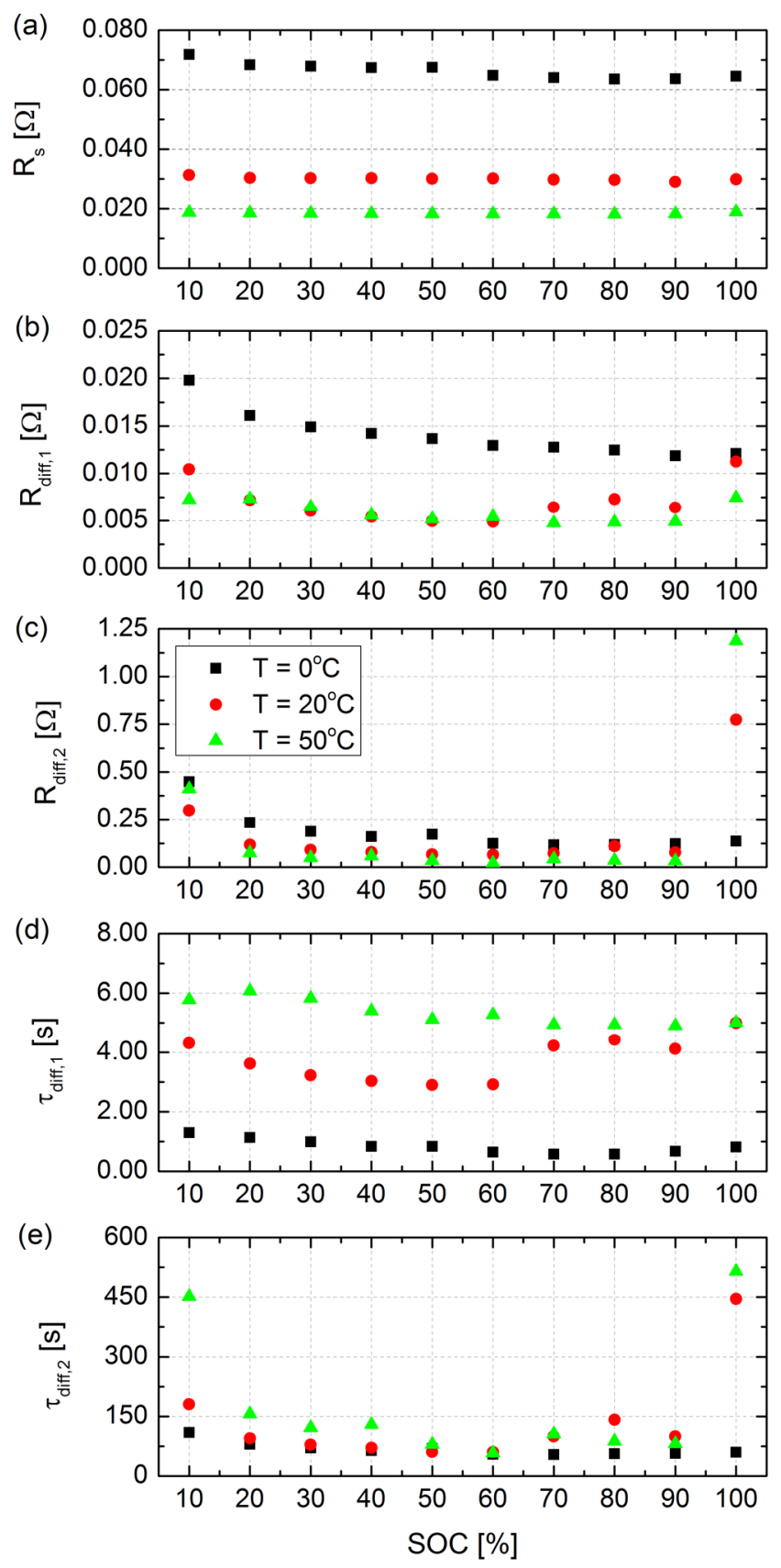

Figure 6: ECM parameters obtained at $50^{\circ} \mathrm{C}, 20^{\circ} \mathrm{C}$ and $0{ }^{\circ} \mathrm{C}$ and various $\mathrm{SOC}$ by model estimation using current pulses. 
Results displayed in Figure 6 (a) show that $R_{s}$ decreases with increasing temperature and remains relatively constant at all SOCs. $R_{\text {diff, }, 1}$ and $R_{\text {diff, } 2}$ (Figure 6 (b) and (c), respectively) increase with lower temperatures and, at $50^{\circ} \mathrm{C}$ and $20^{\circ} \mathrm{C}$, at high and low SOC. At $0^{\circ} \mathrm{C}$, an increase in $R_{\text {diff, } 1}$ and $R_{\text {diff, }, 2}$ is only evident at low SOC. These observations are consistent with the EIS measurements displayed in Figure 4 (a) to (c), when comparing resistance values $\left(R_{s}, R_{\text {diff, }, 1}\right.$ and $\left.R_{\text {diff }, 2}\right)$ with the respective sections of the real part of the impedance, $Z$ '. Time constants for diffusion processes, $\tau_{\text {diff, },}$ and $\tau_{\text {diff, } 2}$ (Figure 6 (d) and (e)), generally exhibit opposite temperature dependence compared to $R_{\text {diff, },}$ and $R_{\text {diff,2, }}$, i.e. larger values at higher temperatures. In EIS data (when displayed in a Nyquist plot as in Figure 4), larger time constants for the diffusion process correspond to steeper slopes of imaginary vs. real parts of impedance in that frequency regime. The steeper slope arises from larger equivalent values for capacitance. The temperature dependency of $\tau_{\text {diff, },}$ and $\tau_{\text {diff, } 2}$ thus match trends expected from EIS data.

The qualitative comparison of trends observed among estimated parameters and measured EIS data (between $0{ }^{\circ} \mathrm{C}$ and $50{ }^{\circ} \mathrm{C}$ ) demonstrates the consistency between the two methods.

\subsection{Model validation}

Initial validation efforts were focused on the dynamic model performance at various C-rates and temperatures, at an approximately constant SOC of $50 \%$. Future work will include the integration of the model into an observer and validation under variable SOC. For validation under realistic operating conditions, the cell was subjected to load profiles derived from the Artemis drive cycle, as described in Section 2.3. The current profile was scaled to a number of C-rates, ranging from $\mathrm{C} / 2$ to $9 \mathrm{C}$ (with respect to the cell's effective capacity measured at the corresponding temperature). Maximum C-rates were dictated by the cell's power capabilities at the respective temperatures. To justify the assumption of constant SOC, profiles were limited to $5 \mathrm{~min}$.

Figure 7 illustrates measured and simulated cell voltages at $50{ }^{\circ} \mathrm{C}, 20{ }^{\circ} \mathrm{C}, 0{ }^{\circ} \mathrm{C}$ and $-30{ }^{\circ} \mathrm{C}$ and different maximum currents. The results displayed in Figure 7 (a) to (c) show very good agreement between measured and simulated cell voltage at $50{ }^{\circ} \mathrm{C}(9 \mathrm{C}), 20{ }^{\circ} \mathrm{C}(9 \mathrm{C})$ and $0{ }^{\circ} \mathrm{C}(5.4 \mathrm{C})$. A quantitative assessment of model performance was conducted by means of root-mean-square deviation (RMSD), according to

$$
R M S D=\sqrt{\frac{\sum_{t=1}^{n}\left(v_{\text {exp }, t}-v_{\text {sim }, t}\right)^{2}}{n}}
$$

where $v_{\text {exp }, t}$ is the measured and $v_{\text {sim, }}$ the simulated voltage at time $t$, and $n$ the number of measurement points, and maximum residual $\left(\varepsilon_{\max }\right)$ analysis at various temperatures and C-rates. Results are listed in Table 1.
Model performance was found to improve with higher temperature and lower C-rates. The poorest results were obtained at $-30{ }^{\circ} \mathrm{C}$ and a maximal C-rate of $\mathrm{C} / 2$ with $\varepsilon_{\max }$ reaching $68 \mathrm{mV}$ or $2 \%$ of the nominal cell voltage $\left(V_{\text {nom }}=\right.$ $3.3 \mathrm{~V}$ ) and a RMSD of $28 \mathrm{mV}$ or $0.8 \%$ of $V_{\text {nom }}$. Model performance increased significantly at $0{ }^{\circ} \mathrm{C}$ and above with maximal $\varepsilon_{\max }$ values of $48 \mathrm{mV}$ or $1.5 \%$ of $V_{\text {nom }}$ and a maximal RMSD of $8 \mathrm{mV}$ or $0.2 \%$ of $V_{\text {nom }}$ (at $0^{\circ} \mathrm{C}$ and $5.4 \mathrm{C}$ ). The best results were obtained at $20{ }^{\circ} \mathrm{C}$ and $50{ }^{\circ} \mathrm{C}$, where maximal residuals remained within $15 \mathrm{mV}$ or $0.5 \%$ of $V_{\text {nom }}$ and RMSD values did not exceed $3.4 \mathrm{mV}$ or $0.1 \%$ of $V_{\text {nот }}$.
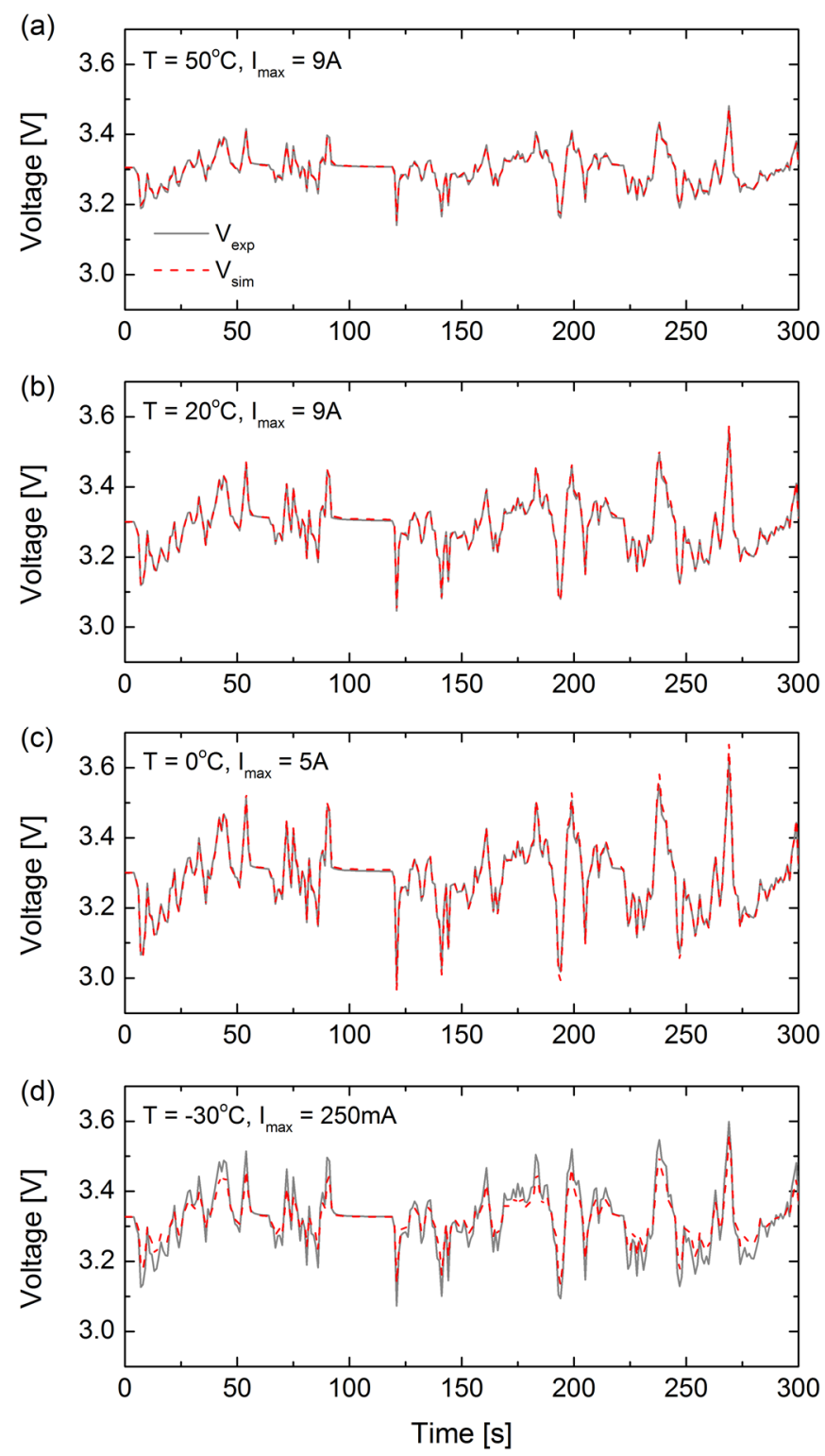

Figure 7: Measured (solid line) and simulated (dashed line) voltage response to Artemis drive cycle profiles recorded at $50{ }^{\circ} \mathrm{C}, 20{ }^{\circ} \mathrm{C}, 0{ }^{\circ} \mathrm{C}$ and $-30{ }^{\circ} \mathrm{C}$ and $50 \%$ SOC. Maximum applied currents are displayed in the graphs. 


\begin{tabular}{|c|c|c|c|c|c|}
\hline \multirow[t]{2}{*}{$\mathrm{T}$} & & \multicolumn{4}{|l|}{$I_{\max }$} \\
\hline & & $250 \mathrm{~mA}$ & $2 \mathrm{~A}$ & $5 \mathrm{~A}$ & $9 \mathrm{~A}$ \\
\hline \multirow{2}{*}{$50^{\circ} \mathrm{C}$} & RMSD [mV] & - & - & 1.5 & 2.7 \\
\hline & {$[\mathrm{mV}]$} & - & - & 5.6 & 10.6 \\
\hline \multirow{2}{*}{$20^{\circ} \mathrm{C}$} & $\mathrm{RMSD}[\mathrm{mV}]$ & - & 0.6 & 1.5 & 3.4 \\
\hline & $\varepsilon_{\max } \quad[\mathrm{mV}]$ & - & 1.3 & 5.3 & 14.9 \\
\hline \multirow{2}{*}{$0^{\circ} \mathrm{C}$} & $\mathrm{RMSD}[\mathrm{mV}]$ & - & 1.9 & 7.7 & - \\
\hline & {$[\mathrm{mV}]$} & - & 5.9 & 48.2 & - \\
\hline \multirow{2}{*}{$-30{ }^{\circ} \mathrm{C}$} & $\mathrm{RMSD}[\mathrm{mV}]$ & 28.2 & - & - & - \\
\hline & {$[\mathrm{mV}]$} & 67.6 & - & - & - \\
\hline
\end{tabular}

Table 1: RMSD and $\varepsilon_{\max }$ values expressing the deviation between measured and simulated voltage when applying an Artemis load profile for $5 \mathrm{~min}$ at various temperatures and maximal currents.

\section{Conclusions}

We have presented a method for model identification and parameter estimation of a low order, parameter-varying linear model, suitable for application in an automotive BMS. Model identification and parameter estimation were based on current pulse measurements, which could be performed during vehicle charging or rest periods. Modelling efforts were focused on diffusion as the predominant dynamic process relevant for practical applications with sampling frequencies limited to $5 \mathrm{~Hz}$. The model structure allows for high variability of parameters with SOC and temperature. Correspondence between time and frequency domain data was established and maintained throughout the modelling process. The model was shown to be plausible using current profiles based on a drive cycle (at constant SOC) at $50{ }^{\circ} \mathrm{C}$, $20{ }^{\circ} \mathrm{C}, 0^{\circ} \mathrm{C}$ and $-30{ }^{\circ} \mathrm{C}$ and at $\mathrm{C}$-rates ranging from $\mathrm{C} / 2$ to $9 \mathrm{C}$. At temperatures of $0{ }^{\circ} \mathrm{C}$ and above, $\varepsilon_{\max }$ values of $48 \mathrm{mV}$ or $1.5 \%$ of $V_{\text {nom }}$ and a maximal RMSD of $8 \mathrm{mV}$ or $0.2 \%$ of $V_{\text {nom }}$ were obtained.

Future work includes the improvement of model performance at very low temperatures and the implementation of the model in a state observer, capable of estimating the SOC in a wide range of operating conditions. Eventually, the model will be extended to include degradation by tracking parameter variations over time and usage.

\section{Acknowledgements}

The authors would like to thank Professor Stephen Duncan for his very helpful guidance and suggestions of system identification approaches in MATLAB ${ }^{\circledR}$.

We would also like to express our appreciation to Dr Mark Tucker, Lead Engineer at Tata Motors European Technical Centre, for his insightful advice and consultation.

This work is funded by the UK Engineering and Physical Sciences Research Council and Jaguar Land Rover Limited.

\section{References}

[1] G. L. Plett, "Extended Kalman filtering for battery management systems of LiPB-based HEV battery packs," Journal of Power Sources, vol. 134, no. 2, pp. 252-261, Aug. 2004.

[2] M. Verbrugge and B. Koch, "Generalized Recursive Algorithm for Adaptive Multiparameter Regression," Journal of The Electrochemical Society, vol. 153, no. 1, p. A187, 2006.

[3] H. He, R. Xiong, H. Guo, and S. Li, "Comparison study on the battery models used for the energy management of batteries in electric vehicles," Energy Conversion and Management, vol. 64, pp. 113-121, 2012.

[4] J. Gomez, R. Nelson, E. E. Kalu, M. H. Weatherspoon, and J. P. Zheng, "Equivalent circuit model parameters of a high-power Li-ion battery: Thermal and state of charge effects," Journal of Power Sources, vol. 196, no. 10, pp. 4826-4831, 2011.

[5] D. Andre, M. Meiler, K. Steiner, C. Wimmer, T. Soczka-Guth, and D. U. Sauer, "Characterization of high-power lithium-ion batteries by electrochemical impedance spectroscopy. I. Experimental investigation," Journal of Power Sources, vol. 196, no. 12, pp. 5334-5341, Jun. 2011.

[6] M. Verbrugge, D. Frisch, and B. Koch, "Adaptive Energy Management of Electric and Hybrid Electric Vehicles," Journal of The Electrochemical Society, vol. 152, no. 2, p. A333, 2005.

[7] E. Barsoukov, J. H. Kim, D. H. Kim, K. S. Hwang, C. O. Yoon, and H. Lee, "Parametric analysis using impedance spectroscopy : relationship between material properties and battery performance," vol. 310, pp. 303-310, 2000.

E. Barsoukov and J. R. Macdonald, Impedance spectroscopy - theory, experiment, and applications. John Wiley \& Sons, Inc, 2005.

E. Kim, J. Lee, and K. Shin, "Real-Time Prediction of Battery Power Requirements for Electric Vehicles," in 4th Internation Conference on Cyber-Physical Systems, 2013.

M. André, "The ARTEMIS European driving cycles for measuring car pollutant emissions," Science of The Total Environment, vol. 334-335, no. null, pp. 73-84, Dec. 2004. 